\title{
Comparative Study of Computational Models for Reducing Air Pollution through the Generation of Negative Ions
}

\author{
Paola Ortiz-Grisales ${ }^{1}$, Julián Patiño-Murillo ${ }^{1, *(\mathbb{D})}$ and Eduardo Duque-Grisales ${ }^{1,2}$ (D) \\ 1 Facultad de Ingeniería, Institución Universitaria Pascual Bravo, Calle 73 No. 73A-226 Medellín, Colombia; \\ paola.ortiz@pascualbravo.edu.co (P.O.-G.); e.duque@pascualbravo.edu.co or \\ eduardo.duque@esumer.edu.co (E.D.-G.) \\ 2 Facultad de Estudios Empresariales y de Mercadeo, Institución Universitaria Esumer, \\ Calle 76 No. 80-126 Medellín, Colombia \\ * Correspondence: julian.patino@pascualbravo.edu.co
}

Citation: Ortiz-Grisales, P.;

Patiño-Murillo, J.; Duque-Grisales, E. Comparative Study of Computational Models for Reducing Air Pollution through the Generation of Negative Ions. Sustainability 2021, 13, 7197. https://doi.org/10.3390/su13137197

Academic Editor: Farooq Sher

Received: 7 May 2021

Accepted: 16 June 2021

Published: 27 June 2021

Publisher's Note: MDPI stays neutral with regard to jurisdictional claims in published maps and institutional affiliations.

Copyright: (c) 2021 by the authors. Licensee MDPI, Basel, Switzerland. This article is an open access article distributed under the terms and conditions of the Creative Commons Attribution (CC BY) license (https:// creativecommons.org/licenses/by/ $4.0 /)$.

\begin{abstract}
Today, air quality is one of the global concerns that governments are facing. One of the main air pollutants is the particulate matter (PM) which affects human health. This article presents the modeling of a purification system by means of negative air ions (NAIs) for air pollutant removal, using computational intelligence methods. The system uses a high-voltage booster output to ionize air molecules from stainless steel electrodes; its particle-capturing efficiency reaches up to $97 \%$. With two devices $(5 \mathrm{~cm} \times 2 \mathrm{~cm} \times 2.5 \mathrm{~cm}), 2$ trillion negative ions are produced per second, and the particulate matter (PM 2.5) can be reduced from 999 to $0 \mathrm{mg} / \mathrm{m}^{3}$ in a period of approximately 5 to 7 minutes (in a $40 \mathrm{~cm} \times 40 \mathrm{~cm} \times 40 \mathrm{~cm}$ acrylic chamber). This negative ion generator is a viable and sustainable alternative to reduce polluting emissions, with beneficial effects on human health.
\end{abstract}

Keywords: environmental pollution; air purification; negative ion generators; particulate matter

\section{Introduction}

Both developing and developed world cities are at a crossroads in making the right decisions to ensure a sustainable future [1]. The increasing city pollution levels and their severe effects on human health demand immediate action from governments to combat the consequences of human exposure to low-quality air [2]. Studies have shown that environmental pollution through particulate matter causes different health problems such as respiratory and heart diseases [3-9].

Special attention has been paid to particles with an aerodynamic diameter of $2.5 \mu \mathrm{m}$ (PM 2.5), given their chemical composition and the threat to produce lung diseases [10]. Consequently, PM 2.5 has become a source of significant concern worldwide [11]. The work of Cavalcante et al. indicates that the composition of particulate material varies according to the emission source [12]. Furthermore, the studies of Ramanathan and Feng, Ventura et al., and Cavalcante et al. show that the presence of this pollutant in the atmosphere causes a variety of impacts on vegetation, the environment, and human health $[2,11,13]$.

Different techniques and applications have recently been studied to solve air purification problems, especially in indoor spaces [14]. Techniques such as semiconductor photocatalysis [15-17] and oxidation with ozone [18] stand out. There is also filtration [19,20], use of adsorbents [21], plasma [22], ultraviolet light [23], generation of ions and plasma [24], among others. Alternative filtration technologies based on electrostatic precipitators or negative ion generators have gotten more attention in the academic field due to a lower noise level, lower electricity consumption, lower maintenance cost, and higher cleaning energy efficiency [25].

Regarding the use of air ionization for removing polluting particles, the use of Corona Effect Discharge technology is highlighted [26,27]. Indoor air enhancement with negative 
ions provides air purification results with superior efficiencies $[28,29]$. The research conducted by Nadali et al. [14] concluded that negative ions charge particles by producing a strong electric field that causes movement of charged particles towards interior surfaces; these particles finally settle on the surfaces of the walls and the floor. Guo et al. [30] demonstrated that particulate matter (PM 2.5) in a closed glass chamber $\left(5086 \mathrm{~cm}^{3}\right)$ decreases rapidly from 999 to $0 \mu \mathrm{g} / \mathrm{m}^{3}$ in $80 \mathrm{~s}$ under an operating TENG device frequency of $0.25 \mathrm{~Hz}$. Sawant et al. [31] showed that the negative ion system removed $93 \%$ to $97 \%$ of the fog or smoke particles in $6 \mathrm{~min}$ in a glass chamber $(60 \mathrm{~cm} \times 30 \mathrm{~cm} \times 40 \mathrm{~cm})$. Additionally, Pushpawela et al. [32] highlight the use of negative ions for removing fine PM 2.5-type particles and eliminating cigarette smoke [28].

This article presents the modeling of a system for air purification through the generation of negative ions to remove PM 2.5. For this, experimental data were obtained from a test system with conditions closer to an indoor pollution reduction environment. Then, the data were processed through three computational intelligence systems: Artificial Neural Networks (ANNs), K-Nearest Neighbors (k-NN), or K-neighbors and Vector Support Machine (VSM). These three methods were implemented to identify the computational model that better represents the behavior of the negative ions in the air purification process in the presence of three different pollutants (gasoline, cigarette smoke, and incense).

\section{Materials and Methods}

This research studies the effect of negative ions applied to an enclosed environment to identify the level of air decontamination from three types of pollutants. The tests were conducted in an unventilated transparent acrylic chamber of size $6400 \mathrm{~cm}^{3}$ $(\mathrm{L} \times \mathrm{W} \times \mathrm{H}=40 \mathrm{~cm} \times 40 \mathrm{~cm} \times 40 \mathrm{~cm}$ ), with the pollutant source, the negative ion generator, and a PM2.5 concentration sensor contained inside the chamber. The obtained data were processed and analyzed to compare the computational models' performance that allows estimating the operation of an ionization air purification system.

Figure 1 describes the framework of the employed methodology. The first stage involves the design, simulation, and prototyping of the negative air ionizing system. Then, an experimental design and test setup are proposed for data capture. After the data recollection, the preprocessing activities involve exploring, correcting, and normalizing the database and the division into training and validation sets. The modeling stage intends to train the selected algorithms (ANN, KNN, SVM) with the training data to obtain a suitable process model. The last stage involves evaluating the models with the testing data, calculating the estimation error, and analyzing the results.
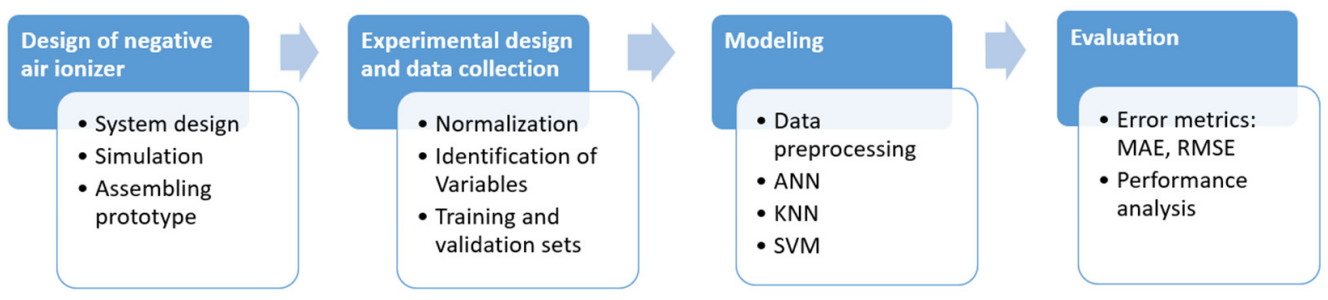

Figure 1. Proposed methodology workflow.

\subsection{Air Purification System through Negative Ions}

Air ionizers are a kind of air purifier that is based on the generation of ions by applying an electric field between two metal electrodes of unequal curvature radius. The ions are accelerated by the electric field and, thanks to the collisions of neutral ions, the momentum is transferred from the ions to the neutral molecules, thus creating an ionic effect that can be used to purify the air: the dust and the particles suspended in the ambient air collect the electrons as they cross the discharge area. These negatively charged particles then settle on grounded surfaces. Air ionizers are a kind of air purifier based on negative ion generation by applying an electric field between two metal electrodes of unequal curvature radius. The electric field accelerates the ions and, thanks to the collisions with neutral ions, the 
momentum is transferred from the ions to the neutral molecules, thus creating an ionic effect that can be used to purify the air: the dust and the particles suspended in the ambient air collect the electrons as they cross the discharge area. These negatively charged particles then settle on grounded surfaces.

Figure 2 presents the air purification process by means of negative ions. A mix of air and particulate matter of 2.5 microns (PM 2.5) pollutes the environment in the figure. Contaminated air enters in contact with negative ions through stainless steel needles (electrodes to favor the ionization), and the separation of purified air and particulate matter occurs as previously described. Negative ionization has been widely used to clean indoor air, with several commercial devices available in the market [33]. However, questions remain about the impacts of these cleaning devices on public health due to their high ozone emission levels [33] and their overall effectiveness as purification systems [34].

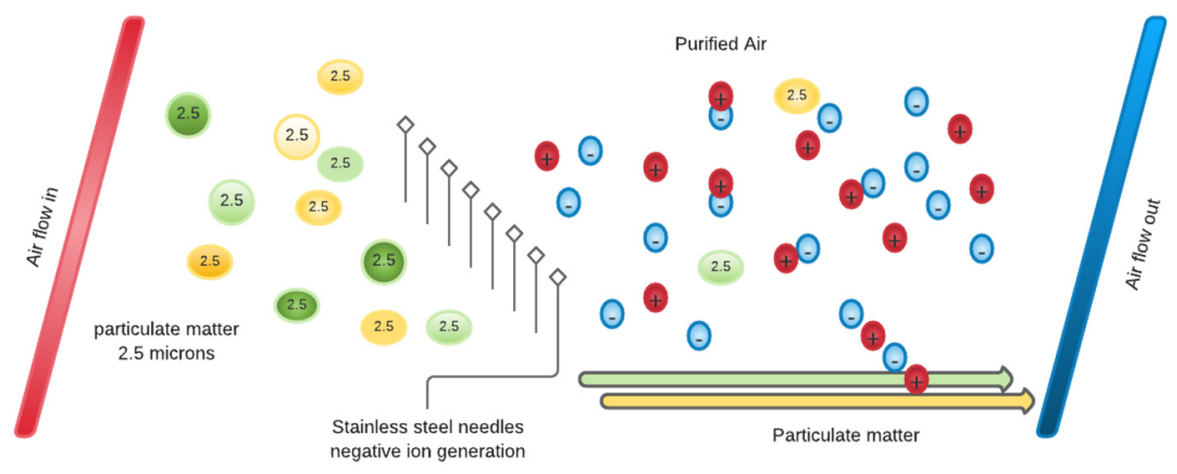

Figure 2. Air purification process through negative ions.

The generation of negative ions is favored by the so-called "Corona Effect" [33]. When a high negative voltage is applied to a conductor or electrode, and the generated electric field is high enough, a corona discharge occurs [12,13]. If a charged conductor or electrode has a type of needle with a sharp tip, the electric field around the tip will be significantly higher than elsewhere, and the air near the electrode can ionize and generate negatively charged particles [34]. The intensity of the corona discharge depends on the shape and size of the conductors and the applied voltage. An irregularly shaped conductor, especially with a sharp tip, results in more corona discharge than a smooth conductor [34]. Largediameter conductors produce a lower corona discharge than small-diameter conductors; the higher the applied voltage, the more negative ions are generated [34]. The closer the distance to the corona point, the higher the detected concentration of negative ions since the continuous generation of negative particles by corona discharge is related to a chain reaction process called electron avalanche [33]. This process requires the design of a voltage multiplication system, which is described below.

\subsubsection{Design of Voltage Multiplier}

The ion generation system requires high voltage levels, usually produced with a voltage multiplier scheme. The Cockcroft-Walton cascade circuit is a high voltage generator, where the application of an AC voltage level at the input produces a higher DC voltage level at the output [35]. These circuit configurations can lead to high voltages from relatively low input values, and they are lighter and cheaper than transformers. The voltage multiplier system is divided into stages. Each stage consists of two diodes and two capacitors, plus an alternating voltage input. The operating principle of this system is the successive charging of capacitors due to the diode-cascade enabling. Each diode presents a voltage loss given by the technical characteristics of the component, obtaining at the output of each stage twice the input voltage minus the loss value. The output voltage of each stage becomes the input for the next one. Figure 3 illustrates the selected configuration. 


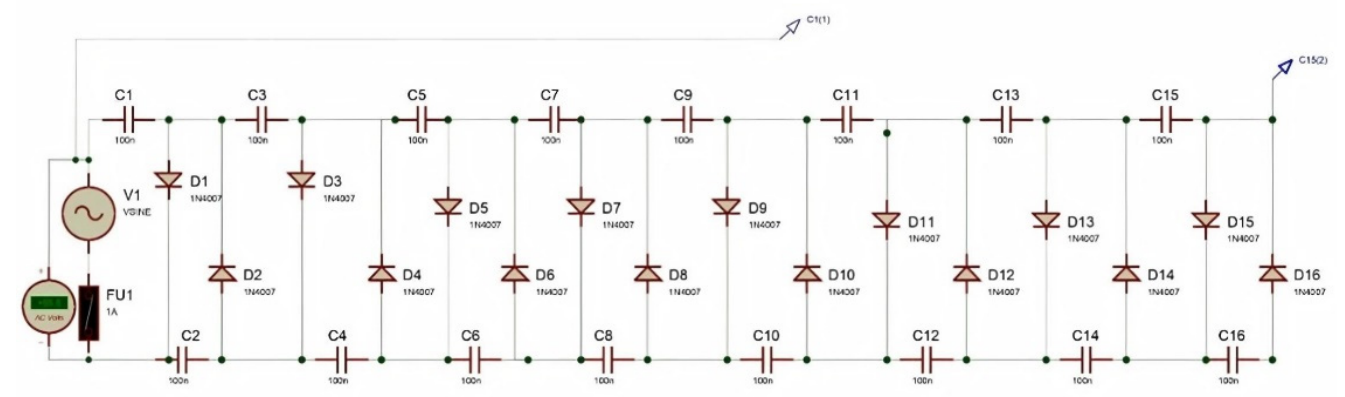

Figure 3. Voltage multiplier circuit.

Using Kirchoff's laws for the analysis of voltage multiplier circuits as described in Figure 3, it can be verified that:

$$
V_{o}=-n V_{i, R M S}
$$

where $V_{o}$ is the output voltage of the circuit, $n$ is the number of multiplication stages, and $V_{i, R M S}$ denotes the effective value of the input voltage applied to the circuit [35]. The design calculations for a voltage multiplier, as shown in Figure 3, result in a capacitor of $100 \mathrm{nf}$, a $1 \mathrm{~N} 4007$ rectifier diode, and an input voltage of 110 volts AC. The designed system is tested in simulation, and Proteus software is used to identify the system's output response and validate the voltage levels.

Figure 4 presents the simulated response of the voltage elevation system for the generation of negative ions. It shows the descending curve generated as the voltage circulates through the voltage multiplier stages until it reaches the stability point corresponding to -7500 volts DC. In this way, the negative ions required for the purification process are generated.

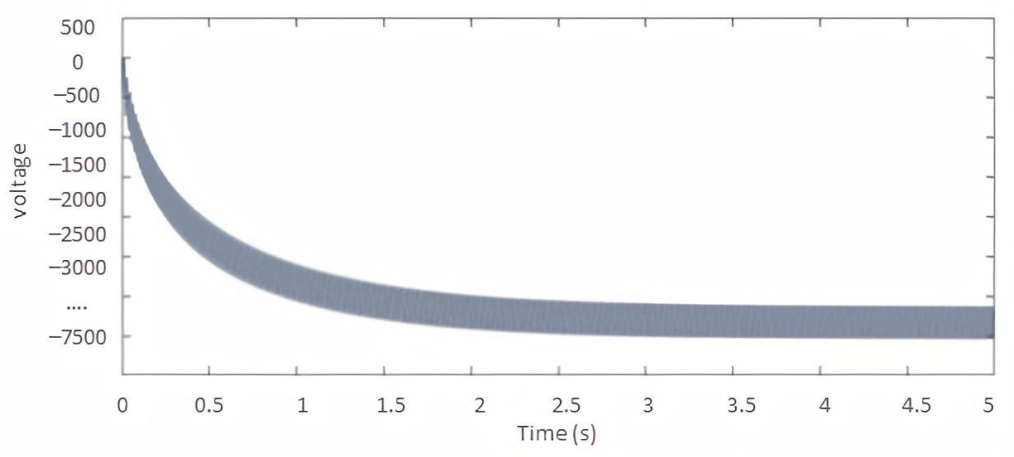

Figure 4. Response of the voltage multiplier system.

The designed voltage multiplier circuit is prototyped, with stainless steel emitting needles (electrodes) used as an interface between the electronic circuit and the environment to transfer the generated negative ions. The system achieves a voltage increase of $441 \mathrm{~V}$ per cycle, leading to an output of $-7500 \mathrm{~V}$ at $10 \mathrm{~mA}$, with 10 trillion ions per second transferred to the environment through the emitting needles arranged at the circuit's output.

\subsubsection{Experimental Setup and Data Collection}

The experimental setup looks to generate data on the effect of negative ions applied inside a $6400 \mathrm{~cm}^{3}$ cubic-shaped container with the electrodes of the voltage multiplier system in contact with the container's atmosphere. In this system, the input air is contaminated with pollutants such as gasoline, cigarettes, and incense; these mostly contain PM 2.5 particles and volatile organic components (VOC), namely:

- Gasoline: carbon dioxide, nitrogen oxide, carbon monoxide, and hydrocarbon molecules;

- Cigarette: nicotine, tar, arsenic, lead, polyaromatic hydrocarbons;

- Incense: carbon monoxide, sulfur dioxide, nitrogen oxide, and formaldehyde. 
This air is brought into contact with the negative ions generated through the electric field produced from the high output voltage in the emitting needles (electrodes). In this way, the contaminating particles bind with the negative ions, taking an excessive weight and adhering to the test surface. Negative ions also cause particles to be attracted to stainless steel needles and the ion-generating electrodes to produce a high density of negative ions (up to 20 trillion ions per second, according to [36]) in two sets used for testing. As a result, cleaner and more purified air remains in the chamber atmosphere. During this process also takes place the measurement of the quantity of the generated ions, the concentration of particulate matter suspended in the air with a diameter less than 2.5 microns (PM 2.5), the concentration of volatile organic compounds (TVOC), the concentration of formaldehyde or methanal (HCHO), $\mathrm{RH}$ and the temperature. These variables represent the required experimental data to generate the computational models representing the process.

\subsection{Computational Modeling of the Effects of Ionization in the Reduction of PM 2.5 Particles}

This work claims to obtain computational models from the experimental data of the PM 2.5 concentration levels in a test system of air purification with negative ions, applying pollutants such as gasoline, cigarettes, and incense. We want to represent system behavior through the exploration of three computational modeling algorithms, namely, Artificial Neural Networks (ANN), K-Nearest Neighbors (KNN), and Vector Support Machine (SVM).

\subsubsection{Artificial Neural Networks (ANN)}

An ANN is made up of many interconnected units called neurons, which have a certain natural tendency to learn from the information in the outside world [37]. This type of network provides solutions to specific problems using a training process. The network learns from its errors through training, and a model is obtained to describe the studied phenomenon as accurately as possible [38].

ANN models are used as very powerful machine learning algorithms for time series prediction of different engineering applications. The ANN model consists of an input layer, hidden layers, and an output layer. Each hidden layer has weights and skew parameters to manage neurons. An activation function is used to transfer the data from the hidden layers to the output layer. Learning algorithms are employed to select the weights within the neural network structure. The weight selection is based on performance measurements such as the mean square error (MSE).

\subsubsection{The K-Nearest Neighbors (KNN) Model}

The KNN algorithm is one of the traditional machine learning algorithms used for data classification [39]. KNN algorithms use K neighbor values to find the closest point between objects. The $\mathrm{K}$ value is used to find the closest points in the feature vectors, and the value must be unique. In this research's algorithm, the Euclidean distance function (Di) was applied to find the closest neighbor in the feature vector, where $x_{1}, x_{2}, y_{1}$, and $y_{2}$ represent the input data variables.

$$
D_{i}=\sqrt{\left(x_{1}-x_{2}\right)^{2}-\left(y_{1}-y_{2}\right)^{2}}
$$

\subsubsection{Vector Support Machine (SVM)}

The SVM is a learning method with theoretical background in statistical learning theory [40], originally developed to perform classification tasks. However, it has been widely used to solve regression problems with a Support Regression Machine (SVR) method. The SVM-produced model depends on a subset of the training data because the cost function to build the model only considers the training points that are beyond a defined margin value. Similarly, the model produced by the SVR only depends on a subset of the training data because the cost function to build the model ignores any training datum that is close (within an $\varepsilon$ threshold) to the model's prediction. 


\subsubsection{Model Performance Measuring}

Performance measurement approaches, such as Root Mean Square Error (RMSE) and Mean Absolute Error MAE were applied to evaluate the ability of the proposed models to predict the decrease in the PM 2.5 concentration due to the effect of the negative ions on the test environment. The RMSE is calculated from the sum of the individual squared errors. The MAE involves the sum of the errors' magnitudes (absolute values) to obtain the 'total error' divided by the number of errors [41]. The statistical expressions used are defined as follows:

- $\quad$ Root Mean Square Error (RMSE):

$$
\text { RMSE }=\sqrt{\sum_{i=1}^{N} \frac{(y-\hat{y})^{2}}{N}}
$$

- Mean Absolute Error (MAE):

$$
\text { MAE }=\sum_{i=1}^{N} \frac{|y-\hat{y}|^{2}}{N}
$$

Variable $y$ represents the observed experimental data, $\hat{y}$ represents the data estimated by the model, and $N$ denotes the total amount of data.

\section{Results}

\subsection{Factorial Design of the Experiment}

A $2 \mathrm{k}$ factorial design of experiments was performed with the Minitab software to determine the impact of the variables affecting the air purification process through negative ions. Factorial designs are helpful in experiments that include several variables to study the overall effect on a particular response. The $2 \mathrm{k}$ factorial design is the most widely used because the factors have only two levels, quantitative or qualitative, and $k$ represents the number of factors to analyze [42]. This design allows exploring a chosen area of the experimental domain; it also allows finding a promising direction for further optimization [43].

The selected experimental design corresponds to the $2 \mathrm{k}$ series which has the factors Ions, Gasoline, Cigarette, and Incense as independent variables. Each one is run at two levels. This design is called a $2^{4}$ factorial design. The main objective is to evaluate the impact of these factors on the amount of particulate matter (PM 2.5), HCHO, and TVOC present in the environment. The levels of the factors are called low and high. In this case, the level selection indicates that it is applied (high, value 1), or that the factor is not applied (low, value -1 ). The $2 \mathrm{k}$ factorial design requires a reliability percentage score over $60 \%$ to consider the effects of the factors in the output as significant.

After processing the data for the $2 \mathrm{k}$ factorial design of experiments using the Minitab software, a reliability of $77.04 \%$ was obtained for the influence of the factors on PM 2.5. On the other hand, the reliability of the pollutant measuring tests for $\mathrm{HCHO}(38.97 \%)$ and TVOC (58.05\%) scored under the significance threshold. The low level of reliability for $\mathrm{HCHO}$ and TVOC is attributed to the small number of repetitions in the experiment (considering that human error in the sampling is minimized with a higher number of repetitions). Figure 5 illustrates the impacts of the presence (1) and absence $(-1)$ of each factor on the concentration of PM 2.5 pollutant, measured in $\mu \mathrm{g} / \mathrm{m}^{3}$, from the $2 \mathrm{k}$ factorial design.

It is possible to determine that particulate matter decreases when negative ions are present in the environment (Figure 5a). For cigarette (Figure 5b) and gasoline (Figure 5d) pollutants, the steep variation indicates a significant impact on the concentration of PM 2.5. Meanwhile, the incense (Figure 5c) increases the concentration of PM 2.5, but the change is not as significant as the other contamination sources. This behavior shows the profound impact that the generation of negative ions offers to decrease PM 2.5 in the test environment and highlights their role as a reducing agent for this type of pollutant. 


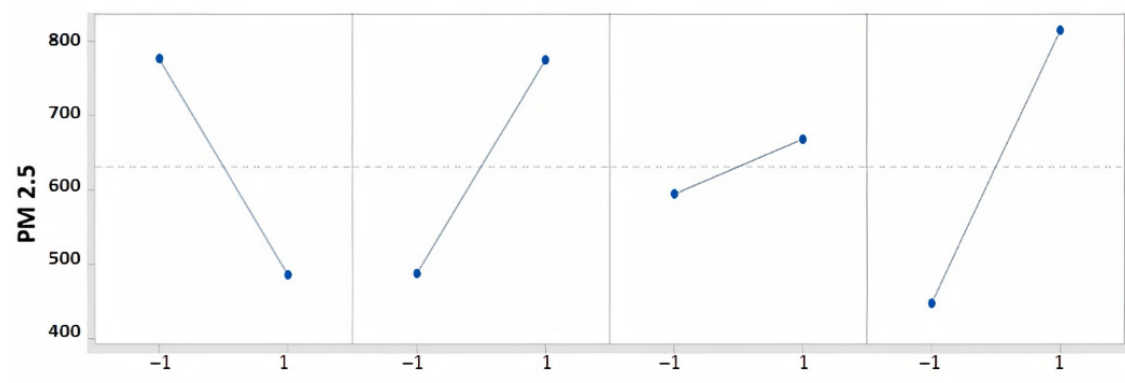
(a) Ions
(b) Cigarette
(c) Incense
(d) Gasoline

Figure 5. The graphs depict the average maximum value of PM 2.5 concentration $\left(\mu \mathrm{g} / \mathrm{m}^{3}\right)$ in the presence (1) and absence ( -1 ) of each experimental factor (ions, cigarette, incense, or gasoline). Each graph is a discrete representation of a pair of points in a two-dimensional coordinated system with values from the factorial experimental design. The solid line is drawn to accentuate the variation of those maximum values of PM2.5 in each case.

On the other hand, Figures 6-8 show the variation in the concentration level of the particulate material PM 2.5 in the presence of each pollutant independently, and the effect of increasing the concentration of negative ions.

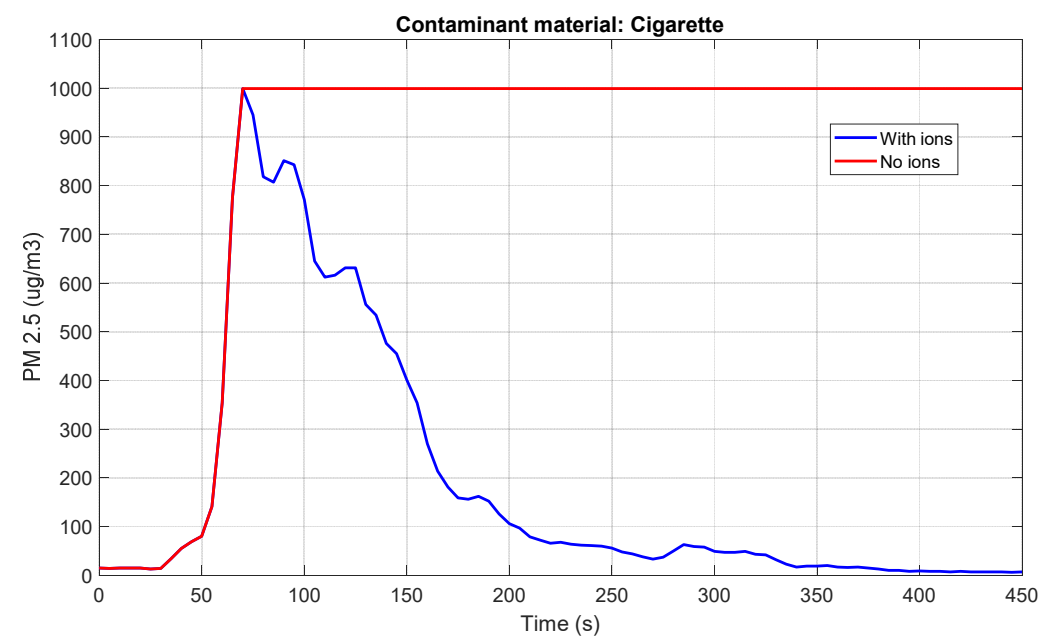

Figure 6. Concentration of PM 2.5 caused by the contaminant Cigarette (red) and the effect of the presence of negative ions (blue).

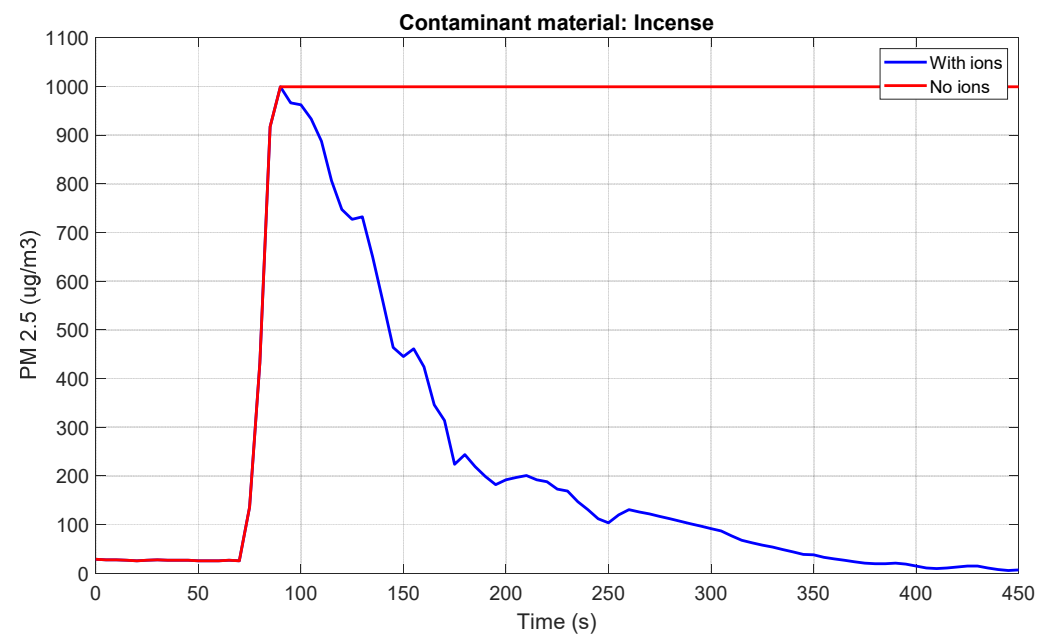

Figure 7. Concentration of PM 2.5 caused by the contaminant Incense (red) and the effect of the presence of negative ions (blue). 


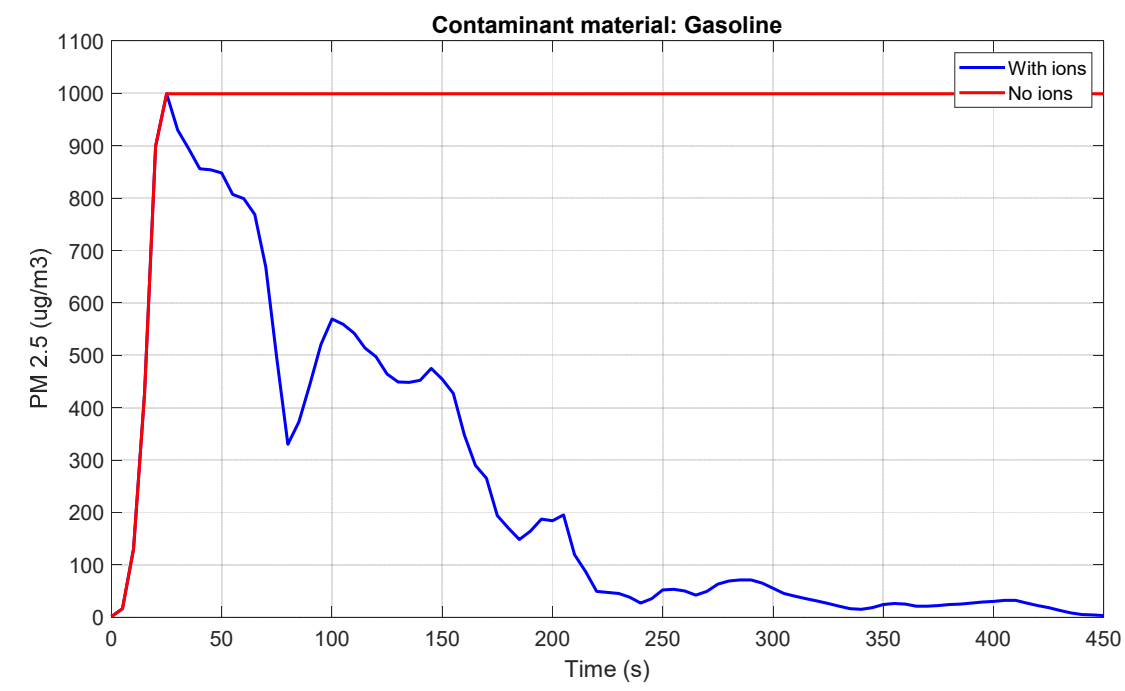

Figure 8. Concentration of PM 2.5 particulate material caused by the contaminant Gasoline (red) and the effect of the presence of negative ions (blue).

For all pollutants, the PM 2.5 concentration reached the sensor's maximum measurement saturation level (around $1000 \mu \mathrm{g} / \mathrm{m}^{3}$ ), although for gasoline, it does so in half the time it takes for cigarettes and incense. Once this level of saturation is reached, the negative ion generation system comes into action, and the concentration of PM 2.5 decreases, taking between 4 and $5 \mathrm{~min}$ to reach zero levels.

These results are in line with Sawant et al. [31], who, using a negative ion system, eliminated between $93 \%$ and $97 \%$ of the cigarette smoke particles in $6 \mathrm{~min}$ in an unventilated glass container of $7200 \mathrm{~cm}^{3}(\mathrm{~L} \times \mathrm{W} \times \mathrm{H}=60 \mathrm{~cm} \times 30 \mathrm{~cm} \times 40 \mathrm{~cm})$. In our tests, the reduction of PM 2.5 particles due to cigarette smoke takes around five minutes to reach 0 levels of concentration (Figure 6), for a volume of $6400 \mathrm{~cm}^{3}$. However, there are better reported rates of PM 2.5 reduction due to negative ion generation, using more advanced techniques like TriboElectric Negative Generation (TENG) devices. Guo et al. [30] demonstrated that particulate matter (PM 2.5) in a closed glass chamber $\left(5086 \mathrm{~cm}^{3}\right)$ decreases rapidly from 999 to $0 \mu \mathrm{g} / \mathrm{m}^{3}$ in $80 \mathrm{~s}$ under an operating TENG device frequency of $0.25 \mathrm{~Hz}$.

\subsection{Comparison of the Obtained Computational Models}

The experimental data were processed using the MATLAB 2020 software tool Algorithms which was implemented to generate computational models that allow estimating the reduction in the concentration of PM 2.5 from the presence of negative ions for each of the pollutants analyzed. In each case, the following techniques were used: artificial neural network (ANN), K-Nearest Neighbors (KNN), and Vector Support Machine (SVM).

The simulation of the responses was executed using a computer system with an i5 processor and 8 GB RAM to process all the required tasks. The data were normalized to favor the performance of the computational methods. Each model was identified using $70 \%$ of the data for training and the remaining $30 \%$ for validation.

Figures 9-11 show the comparison among the experimental data and the obtained computational models from each technique to estimate the concentration of PM 2.5 in the presence of negative ions for the contaminants Cigarette, Incense, and Gasoline. The figures show that the estimated computational models captured the behavior trend of the observed concentration, where the $x$-axis represents time in seconds and the $y$-axis-the PM 2.5 data. It can also be observed that the estimation with the SVM method in all cases ended up reaching negative values, which are not plausible for the actual behavior of the estimated variable.

To analyze the performance of the different obtained models for the estimation of PM2.5 in the presence of negative ions, the RMSE (Root Mean Square Error) and the MAE 
(Mean Absolute Error) metrics were used. These prediction errors can help determine how the expected values deviate from the values observed in the experimentation.

Table 1 summarizes the prediction results obtained by each of the models during the training and testing phases. According to the evaluation metrics (RMSE and MAE), the values estimated by the prediction models were very close to the experimental ones. In all the cases evaluated, the models obtained with the SVM technique reached the highest levels of error, being the model for the contaminant Incense, the one that presented the largest amount of error according to the metrics used. On the other hand, the model with the closest approximation and best response in estimating each pollutant corresponds to the one obtained using the KNN technique.

(a) KNN Cigarette

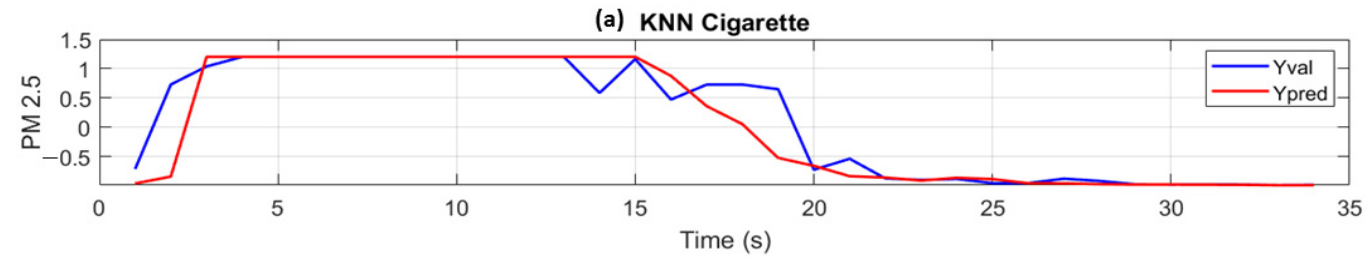

(b) ANN Cigarette

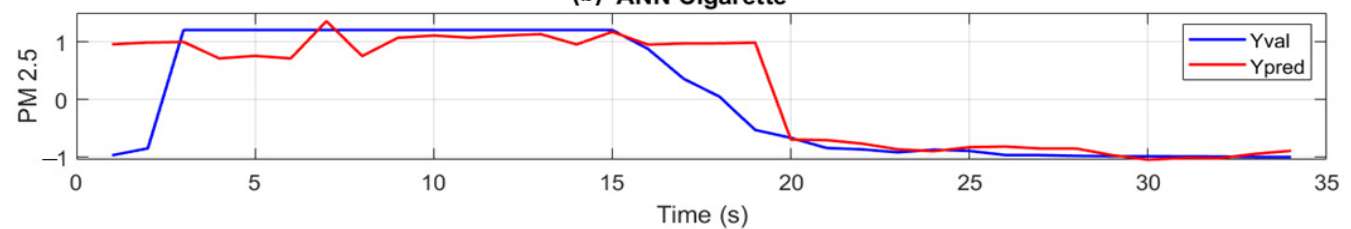

(c) SVM Cigarette

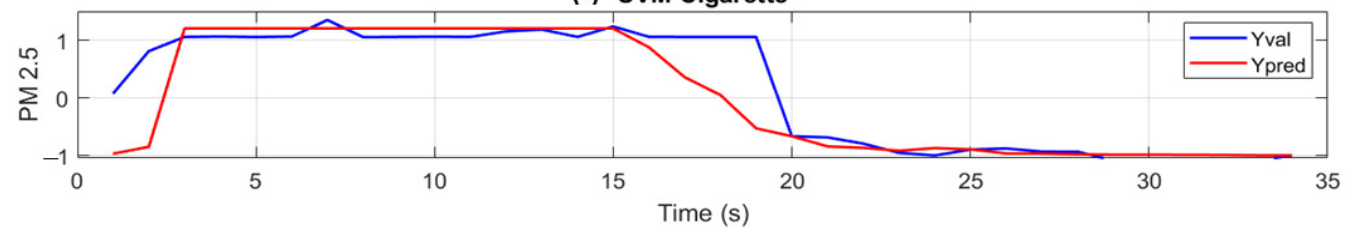

Figure 9. Comparison of the computational models for estimating the normalized concentration of PM 2.5 caused by the cigarette pollutant with the (a) KNN, (b) ANN, and (c) SVM techniques.

(a) KNN Incense

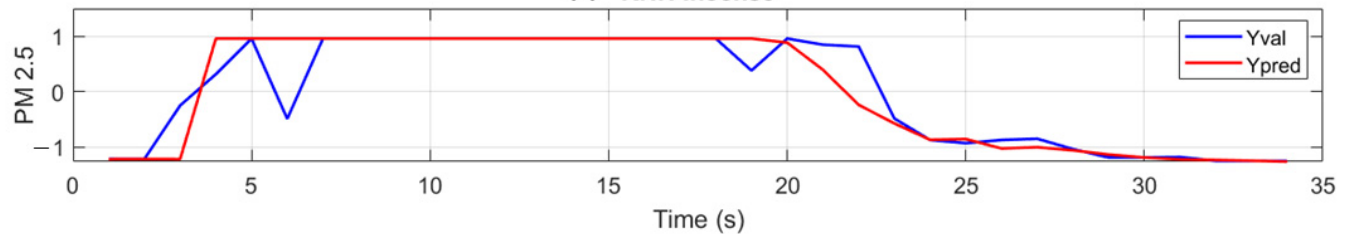

(b) ANN Incense

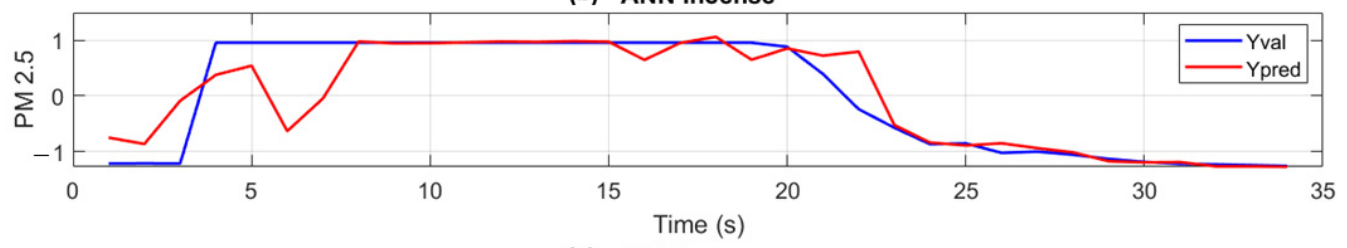

(c) SVM Incense

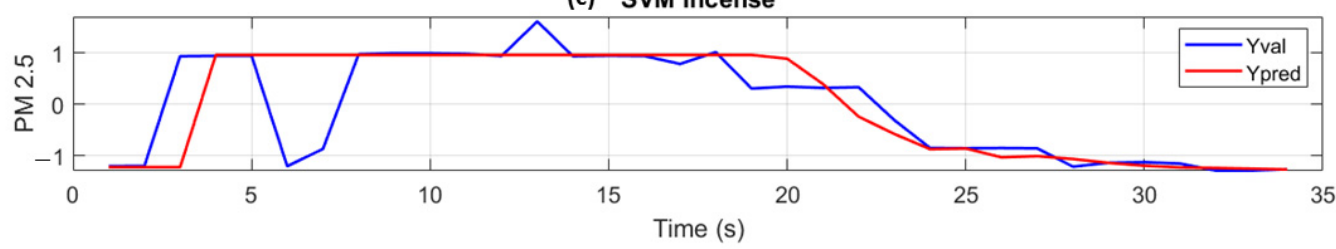

Figure 10. Comparison of the computational models for estimating the normalized concentration of PM 2.5 caused by the Incense pollutant with the (a) KNN, (b) ANN, and (c) SVM techniques. 


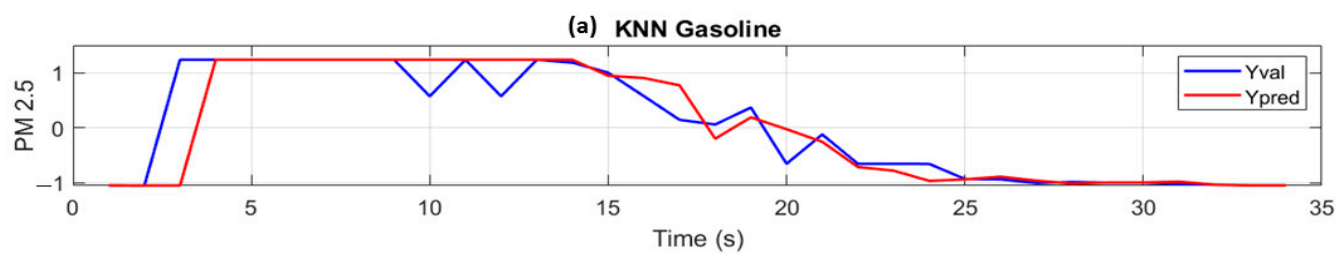

(b) ANN Gasoline

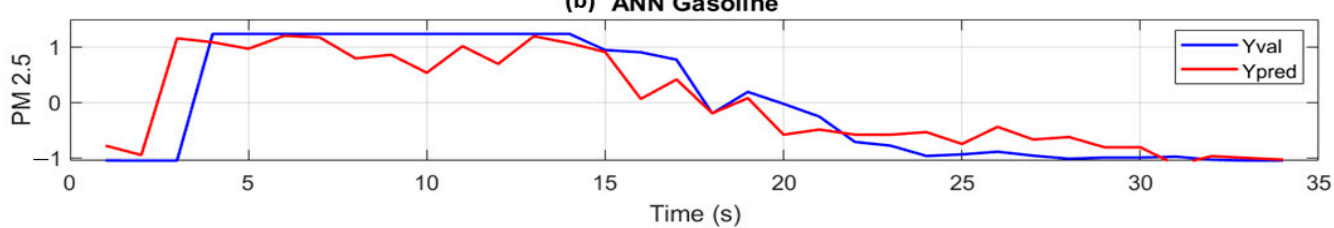

(c) SVM Gasoline

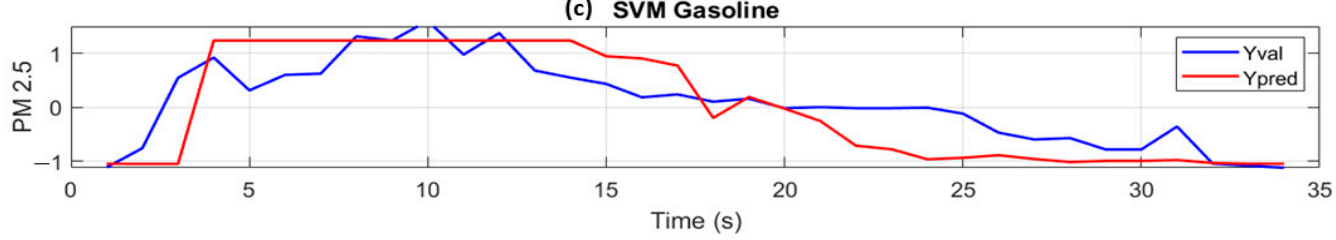

Figure 11. Comparison of the computational models for estimating the normalized concentration of PM 2.5 caused by the Gasoline pollutant with the (a) KNN, (b) ANN, and (c) SVM techniques.

Table 1. Error metrics for the applied computational intelligence methods.

\begin{tabular}{cccc}
\hline Pollutant & Method & RMSE Error & MAE Error \\
\hline \multirow{3}{*}{ Cigarette } & ANN & 0.3957 & 0.1915 \\
& KNN & 0.3906 & 0.1733 \\
& SVM & 0.4746 & 0.2594 \\
\hline \multirow{3}{*}{ Incense } & ANN & 0.4758 & 0.4511 \\
& KNN & 0.3900 & 0.1718 \\
& SVM & 1.1167 & 0.5616 \\
\hline \multirow{2}{*}{ Gasoline } & ANN & 0.4636 & 0.2426 \\
& KNN & 0.4615 & 0.1925 \\
& SVM & 0.5298 & 0.4092 \\
\hline
\end{tabular}

\subsection{Discussion of Results}

The use of computational models based on artificial intelligence (AI) techniques has been growing. AI is already used today in numerous business and production applications, including automation, language processing, and productive data analytics. The advantages of using AI techniques involve better accuracy, human error minimization, and reduced time for information analysis. However, AI also requires enough data availability and adequate processing and interpretation of the information. From the experimental study in this work, we can evidence the potential of these computational models in air purification tasks and the need for data preprocessing (like normalization) to improve performance.

In this sense, the application of artificial intelligence techniques to predict PM 2.5 concentration has been studied previously in the literature. Ma et al. [44] used neural network methods compared with traditional approaches to estimate PM 2.5 dispersion in broad geographical zones, reaching lower RMSE values than the traditional meteorological approaches. Furthermore, Tian-Cheng et al. [45], Zhu et al. [46], and Zhou et al. [47] proposed ANN as an optimization method to predict PM2.5 concentration in outdoor environments. However, those works focus on different approaches and experimental tests significantly different from the ones reported in this study, making it challenging to compare the reported accuracy values. According to the data and the procedure performed, the $\mathrm{KNN}$ technique is the best method to represent the reduction in the concentration of PM 2.5 in the presence of negative ions for the cigarette, incense, and gasoline pollutants. The developed model can quickly and economically predict the effectiveness of the generation 
of negative ions in air decontamination processes and, therefore, guide the development of effective strategies for better sustainability and air quality management through the removal of particulate matter.

\section{Conclusions}

Modeling and predicting the effectiveness of air decontamination methods using computational algorithms is an useful action for environmental protection. Computational models were developed to predict the impact of negative ions on the reduction of particulate material PM 2.5 in the environment by using the data obtained in an experimental setup. The development of new methodologies using advanced algorithms inspired by artificial intelligence techniques can help evaluate strategies to improve the quality of the environment. In the proposed methodology, artificial neural networks (ANN), K-Nearest Neighbors (KNN), and Vector Support Machine (SVM) algorithms were used to predict the concentration decrease, and its performance was statistically assessed. The following conclusions can be drawn:

The present study explored alternative artificial intelligence methods to predict the reduction in particulate matter PM 2.5 from experimental data from a test setup in a $6400 \mathrm{~cm}^{3}$ container. The proposed experimental design allowed obtaining the data to implement artificial intelligence models to predict the effects of negative ions in the reduction of PM 2.5 generated by contaminants such as cigarettes, incense, and gasoline.

Secondly, computational models can be developed by using the Artificial Neural Networks (ANN), the K-Nearest Neighbors (KNN) and the Support Vector Machine (SVM) to predict the reduction of PM 2.5 concentration in the air. Remarkably, the prediction values were very close to the observation values for the different methods and contaminants. The prediction results with the KNN technique were superior to those generated from ANN and SVM, for both error metrics of RMSE and MAE.

In addition, this research confirms that negative ions are an effective method and a promising option for improving environmental quality, which can be implemented to reduce pollution due to the presence of 2.5 micron particulate matter in the air. The reduction times of around five minutes for the different contaminants are consistent with those reported in literature for enclosed spaces. The models developed can be implemented to predict the efficiency of strategies to improve air quality in closed spaces, contributing to environmental sustainability. The robustness and efficiency of the proposed methods for predicting the effectiveness of negative ions in air decontamination can be examined in future work. Additionally, other future work could involve the implementation of these methods in open-space environments.

Author Contributions: P.O.-G.: conceptualization, methodology, validation, formal analysis, investigation, resources, writing-original draft preparation; J.P.-M.: conceptualization, methodology, investigation, supervision, writing-review and editing, supervision, project administration, funding acquisition; E.D.-G.: conceptualization, methodology, investigation, resources, writing-review. All authors have read and agreed to the published version of the manuscript.

Funding: This research was funded by the Direction of Technology and Innovation of the Institución Universitaria Pascual Bravo and the Direction of Investigations of the Institución Universitaria Esumer, project identified with the code IN201904 "Technological adaptation of a conventional bicycle with hybrid energy generation for air purification in the city of Medellín" and project identified with the code IN202106 "Eco-mobility system: hybrid energy generation for air purification".

Institutional Review Board Statement: Not applicable.

Informed Consent Statement: Not applicable.

Data Availability Statement: Not applicable.

Conflicts of Interest: The authors declare no conflict of interest. 


\section{References}

1. Rojas Arenas, I.D. Del desarrollo económico al desarrollo económico endógeno: Una mirada desde el pensamiento complejo. Rev. Cintex 2018, 23, 12-23. [CrossRef]

2. Ramanathan, V.; Feng, Y. Air pollution, greenhouse gases and climate change: Global and regional perspectives. Atmos. Environ. 2009, 43, 37-50. [CrossRef]

3. Sahu, S.K.; Kota, S.H. Significance of PM2.5 air quality at the Indian capital. Aerosol Air Qual. Res. 2017, 17, 588-597. [CrossRef]

4. Guaita, R.; Pichiule, M.; Maté, T.; Linares, C.; Díaz, J. Short-term impact of particulate matter (PM2.5) on respiratory mortality in Madrid. Int. J. Environ. Health Res. 2011, 21, 260-274. [CrossRef] [PubMed]

5. Ortiz, C.; Linares, C.; Carmona, R.; Díaz, J. Evaluation of short-term mortality attributable to particulate matter pollution in Spain. Environ. Pollut. 2017, 224, 541-551. [CrossRef] [PubMed]

6. Fajersztajn, L.; Saldiva, P.; Pereira, L.A.A.; Leite, V.F.; Buehler, A.M. Short-term effects of fine particulate matter pollution on daily health events in Latin America: A systematic review and meta-analysis. Int. J. Public Health 2017, 62, 729-738. [CrossRef] [PubMed]

7. Liu, C.; Chen, R.; Sera, F.; Vicedo-Cabrera, A.M.; Guo, Y.; Tong, S.; Coelho, M.S.; Saldiva, P.H.; Lavigne, E.; Matus, P.; et al. Ambient particulate air pollution and daily mortality in 652 cities. N. Engl. J. Med. 2019, 381, 705-715. [CrossRef]

8. Pope III, C.A.; Dockery, D.W. Health effects of fine particulate air pollution: Lines that connect. J. Air Waste Manag. Assoc. 2006, 56, 709-742. [CrossRef]

9. Amri, F. Carbon dioxide emissions, output, and energy consumption categories in Algeria. Environ. Sci. Pollut. Res. 2017, 24, 14567-14578. [CrossRef]

10. Choi, S.W.; Kim, B.H. Applying PCA to Deep Learning Forecasting Models for Predicting PM2.5. Sustainability 2021, 13, 3726. [CrossRef]

11. Ventura, L.M.B.; Mateus, V.L.; de Almeida, A.C.S.L.; Wanderley, K.B.; Taira, F.T.; Saint'Pierre, T.D.; Gioda, A. Chemical composition of fine particles (PM2.5): Water-soluble organic fraction and trace metals. Air Qual. Atmos. Health 2017, 10, 845-852. [CrossRef]

12. Cavalcante, R.M.; Rocha, C.A.; De Santiago, Í.S.; Da Silva, T.F.; Cattony, C.M.; Silva, M.V.; Silva, I.B.; Thiers, P.R. Influence of urbanization on air quality based on the occurrence of particle-associated polycyclic aromatic hydrocarbons in a tropical semiarid area (Fortaleza-CE, Brazil). Air Qual. Atmos. Health 2017, 10, 437-445. [CrossRef]

13. Liu, W.; Huang, J.; Lin, Y.; Cai, C.; Zhao, Y.; Teng, Y.; Mo, J.; Xue, L.; Liu, L.; Xu, W.; et al. Negative ions offset cardiorespiratory benefits of PM2. 5 reduction from residential use of negative ion air purifiers. Indoor Air 2021, 31, 220-228. [CrossRef] [PubMed]

14. Nadali, A.; Arfaeinia, H.; Asadgol, Z.; Fahiminia, M. Indoor and outdoor concentration of PM10, PM2. 5 and PM1 in residential building and evaluation of negative air ions (NAIs) in indoor PM removal. Environ. Pollut. Bioavailab. 2020, 32, 47-55. [CrossRef]

15. Chen, P.; Wang, H.; Liu, H.; Ni, Z.; Li, J.; Zhou, Y.; Dong, F. Directional electron delivery and enhanced reactants activation enable efficient photocatalytic air purification on amorphous carbon nitride co-functionalized with O/La. Appl. Catal. B Environ. 2019, 242, 19-30. [CrossRef]

16. Kubacka, A.; Fernandez-Garcia, M.; Colon, G. Advanced nanoarchitectures for solar photocatalytic applications. Chem. Rev. 2012, 112, 1555-1614. [CrossRef]

17. Qian, X.; Fuku, K.; Kuwahara, Y.; Kamegawa, T.; Mori, K.; Yamashita, H. Design and functionalization of photocatalytic systems within mesoporous silica. ChemSusChem 2014, 7, 1528-1536. [CrossRef]

18. Kwong, C.W.; Chao, C.Y.; Hui, K.S.; Wan, M.P. Removal of VOCs from indoor environment by ozonation over different porous materials. Atmos. Environ. 2008, 42, 2300-2311. [CrossRef]

19. Waring, M.S.; Siegel, J.A.; Corsi, R.L. Ultrafine particle removal and generation by portable air cleaners. Atmos. Environ. 2008, 42, 5003-5014. [CrossRef]

20. Bekö, G.; Fadeyi, M.O.; Clausen, G.; Weschler, C.J. Sensory pollution from bag-type fiberglass ventilation filters: Conventional filter compared with filters containing various amounts of activated carbon. Build. Environ. 2009, 44, 2114-2120. [CrossRef]

21. Monpezat, A.; Topin, S.; Deliere, L.; Farrusseng, D.; Coasne, B. Evaluation methods of adsorbents for air purification and gas separation at low concentration: Case studies on xenon and krypton. Ind. Eng. Chem. Res. 2019, 58, 4560-4571. [CrossRef]

22. Van Durme, J.; Dewulf, J.; Sysmans, W.; Leys, C.; Van Langenhove, H. Efficient toluene abatement in indoor air by a plasma catalytic hybrid system. Appl. Catal. B Environ. 2007, 74, 161-169. [CrossRef]

23. Kowalski, W. Ultraviolet Germicidal Irradiation Handbook: UVGI for Air and Surface Disinfection; Springer Science \& Business Media: New York, NY, USA, 2010. [CrossRef]

24. Nishikawa, K.; Nojima, H. Air purification effect of positively and negatively charged ions generated by discharge plasma at atmospheric pressure. Jpn. J. Appl. Phys. 2001, 40, L835. [CrossRef]

25. Xu, F.; Luo, Z.; Bo, W.; Zhao, L.; Gao, X.; Fang, M.; Cen, K. Experimental investigation on charging characteristics and penetration efficiency of PM2.5 emitted from coal combustion enhanced by positive corona pulsed ESP. J. Electrost. 2009, 67, 799-806. [CrossRef]

26. Nunayon, S.S.; Zhang, H.H.; Jin, X.; Lai, A.C. Experimental evaluation of positive and negative air ions disinfection efficacy under different ventilation duct conditions. Build. Environ. 2019, 158, 295-301. [CrossRef]

27. Huang, R.; Agranovski, I.; Pyankov, O.; Grinshpun, S. Removal of viable bioaerosol particles with a low-efficiency HVAC filter enhanced by continuous emission of unipolar air ions. Indoor Air 2008, 18, 106-112. [CrossRef] 
28. Černecký, J.; Valentová, K.; Pivarčiová, E.; Božek, P. Ionization impact on the air cleaning efficiency in the interior. Meas. Sci. Rev. 2015, 15, 156-166. [CrossRef]

29. Shabani, B.; Hafttananian, M.; Khamani, S.; Ramiar, A.; Ranjbar, A.A. Poisoning of proton exchange membrane fuel cells by contaminants and impurities: Review of mechanisms, effects, and mitigation strategies. J. Power Sources 2019, 427, 21-48. [CrossRef]

30. Guo, H.; Chen, J.; Wang, L.; Wang, A.C.; Li, Y.; An, C.; He, J.H.; Hu, C.; Hsiao, V.K.; Wang, Z.L. A highly efficient triboelectric negative air ion generator. Nat. Sustain. 2021, 4, 147-153. [CrossRef]

31. Sawant, V.; Meena, G.; Jadhav, D. Effect of negative air ions on fog and smoke. Aerosol Air Qual. Res. 2012, 12, 1007-1015. [CrossRef]

32. Pushpawela, B.; Jayaratne, R.; Nguy, A.; Morawska, L. Efficiency of ionizers in removing airborne particles in indoor environments. J. Electrost. 2017, 90, 79-84. [CrossRef]

33. Jiang, S.-Y.; Ma, A.; Ramachandran, S. Negative Air Ions and Their Effects on Human Health and Air Quality Improvement. Int. J. Mol. Sci. 2018, 19, 2966. [CrossRef]

34. Berendt, A.; Budnarowska, M.; Mizeraczyk, J. DC negative corona discharge characteristics in air flowing transversely and longitudinally through a needle-plate electrode gap. J. Electrost. 2018, 92, 24-30. [CrossRef]

35. Maennel, C.G. Improvement in the modelling of a half-wave Cockroft-Walton voltage multiplier. Rev. Sci. Instrum. 2013, 84, 064701. [CrossRef] [PubMed]

36. Terrés-Speziale, A.M. Manejo de la contaminación ambiental intramuros por medio de la generación de iones aéreos electronegativos. Rev. Mex Patol Clin. Med. Lab. 2006, 53, 29-38.

37. Guzmán, A.A.E.; Tzuc, O.M.; Pantí, I.B.; Trujeque, J.R.; Quintana, I.V.P.; Bassam, A. Modelado de partículas PM10 y PM2.5 mediante redes neuronales artificiales sobre clima tropical de San Francisco de Campeche, México. Química Nova 2017, 40, 1025-1034. [CrossRef]

38. May Tzuc, O.; Bassam, A.; Escalante Soberanis, M.A.; Venegas-Reyes, E.; Jaramillo, O.A.; Ricalde, L.J.; El Hamzaoui, Y. Modeling and optimization of a solar parabolic trough concentrator system using inverse artificial neural network. J. Renew. Sustain. Energy 2017, 9, 013701. [CrossRef]

39. Hmoud Al-Adhaileh, M.; Waselallah Alsaade, F. Modelling and Prediction of Water Quality by Using Artificial Intelligence. Sustainability 2021, 13, 4259. [CrossRef]

40. García Nieto, P.J.; Combarro, E.F.; del Coz Díaz, J.J.; Montañés, E. A SVM-based regression model to study the air quality at local scale in Oviedo urban area (Northern Spain): A case study. Appl. Math. Comput. 2013, 219, 8923-8937. [CrossRef]

41. Willmott, C.J.; Matsuura, K. Advantages of the mean absolute error (MAE) over the root mean square error (RMSE) in assessing average model performance. Clim. Res. 2005, 30, 79-82. [CrossRef]

42. Douglas, M. Diseño y Análisis de Experimentos; Limusa Wiley: Segunda Edición, Mexico, 2002.

43. Ferré, J. El Diseño Factorial Completo 2k. Bachelor's Thesis, Universidad Rovira i Virgili, Catalonia, Spain, 2005.

44. Ma, J.; Ding, Y.; Cheng, J.C.; Jiang, F.; Wan, Z. A temporal-spatial interpolation and extrapolation method based on geographic Long Short-Term Memory neural network for PM2.5. J. Clean. Prod. 2019, 237, 117729. [CrossRef]

45. Tian-Cheng, M.A.; Liu, D.M.; Xue-Jie, L.I. Improved particle swarm optimization based fuzzy neural network for PM_ (2.5) concentration prediction. Comput. Eng. Des. 2014, 35, 3258-3262.

46. Zhu, H.; Lu, X. The prediction of PM2.5 value based on ARMA and improved BP neural network model. In Proceedings of the International Conference on Intelligent NETWORKING and Collaborative Systems, Ostrawva, Czech Republic, 7-9 September 2016; IEEE: Piscataway, NJ, USA, 2016; pp. 515-517. [CrossRef]

47. Zhou, S.; Li, W.; Qiao, J. Prediction of PM2.5 concentration based on recurrent fuzzy neural network. In Proceedings of the Control Conference, Seattle, WA, USA, 24-26 May 2017; IEEE: Piscataway, NJ, USA, 2017; pp. 3920-3924. [CrossRef] 